\title{
Morphological and genetic characterization of barley (Hordeum vulgare L.) landraces in the Canary Islands
}

\author{
Jenny Hagenblad (i) Matti W. Leino (D) - Guacimara Hernández Afonso • \\ Desirée Afonso Morales (i)
}

Received: 6 June 2018/Accepted: 19 November 2018/Published online: 4 December 2018

(C) The Author(s) 2018

\begin{abstract}
Barley has been continuously cultivated in the Canary archipelago for millennia, and to this day landrace barley is the preferred choice for cultivation. We have morphologically and genetically characterized 57 landraces collected during the twentyfirst century and conserved in genebanks. The majority of accessions were of the six-row type. Although landraces from the same island tended to be similar, the results showed morphological and genetic diversity both within and in the case of genetic data among islands. Accessions from the easternmost islands were genetically distinct from those from the central and western islands. Accessions from the western islands often had a mixed genetical composition, suggesting more recent exchange of plant material with the
\end{abstract}

Electronic supplementary material The online version of this article (https://doi.org/10.1007/s10722-018-0726-2) contains supplementary material, which is available to authorized users.

J. Hagenblad $(\bowtie)$

IFM Biology, Linköping University, 58183 Linköping,

Sweden

e-mail: Jenny.Hagenblad@liu.se

M. W. Leino

The Archaeological Research Laboratory, Department of Archaeology and Classical Studies, Stockholm

University, 10691 Stockholm, Sweden

G. Hernández Afonso · D. Afonso Morales

Center for the Conservation of Agricultural Biodiversity

of Tenerife (CCBAT), Canary Islands, Spain central islands. The geographic distribution of diversity suggests that conservation of barley genetic resources needs to consider all islands in the archipelago. Landrace barley from the Canary archipelago was found to be morphologically distinct from continental landrace barley. We suggest the uniqueness of Canarian barley, in terms of morphology and genetic diversity, can be used for marketing purposes providing added market value to the crop.

Keywords Landrace barley - Genebank conservation - Morphological characterization · Genetic diversity $\cdot$ Hordeum vulgare

\section{Introduction}

The Canary archipelago is located some $100 \mathrm{~km}$ west of Northern Africa and consists of seven major islands. The first settlers most likely originated from North Africa (Fregel et al. 2009; Hagenblad et al. 2017; Rodriguez-Varela et al. 2017) and colonized the islands during the first millennium AD (RodríguezRodríguez et al. 2011; Atoche Peña 2013). The islands then remained isolated from the mainland, and to a certain extent from each other, until the Hispanic conquest in the fifteenth century (Morales et al. 2009).

The first settlers developed an agrarian society where six-row barley (Hordeum vulgare subsp. 
vulgare) was a major crop (Morales 2010). Barley continued to be a major crop after the Hispanic conquest, and was still the most important winter cereal during the seventeenth century (Sánchez-Manzano Suárez 1984). Its grain, when toasted and ground, has been part of the Canarian diet for centuries. Today, barley is a marginal crop. Although part of the production continues to be used for making "gofio" (toasted flour) the primary use today is grain and straw for livestock (Afonso et al. 2012). With the exception of the eastern islands of Lanzarote and Fuerteventura, barley is generally grown at between 300 and 1000 meters altitude on windward slopes and a little higher on the southern slope of the islands. On the eastern islands barley has been cultivated alternatingly with wheat on marginal, poorer lands, under more unfavourable conditions (González et al. 2005).

In the Canary archipelago cereal cultivation decreased by almost $80 \%$ between the mid-1980s and 2005. An aging rural population, scarce mechanization, and difficulties in commercializing the produce to compete with imported, subsidized, cereals all contributed to the decline. In addition, there was a general abandonment of agriculture. Since 2005, the trend has been reversed and the cultivated area has increased from 900 ha in 2005 to almost 2000 ha in 2016, with the barley cultivation increasing from 91 ha in 2007 to 210 ha in 2014 (Instituto Canario de Estadística [ISTAC] 2018). A revaluation of local agriculture, reintroduction of cereals into traditional rotations with other crops and the acquisition of machinery adapted to the insular orography are some of the factors behind this increase. The cultivated area is small compared to continental standards and Canarian agriculture occurs on very fragmented land. There is a great influence from other sectors such as tourism and traditional crops such as cereals play an important role in conserving the agricultural landscape of the islands.

The barley currently cultivated on the Canary archipelago mostly consists of traditional landraces (Afonso et al. 2012). Being highly adapted to the insular environment landrace barley is suitable for the production of both grain and straw with yields above those of commercial varieties (Hernández et al. 2013). Given the widespread use and the productive value of landrace barley, their conservation is of major importance to Canarian agriculture.
Canarian barley has previously been included in characterizations of Spanish barley (Yahiaoui 2006; Lasa 2008) and as well as barley from Europe, WestAsia and Northern Africa (Pasam et al. 2014), though only in limited numbers. It has recently been shown that farmers have continued to cultivate the type of barley originally brought to the islands by first settlers (Hagenblad et al. 2017). As a consequence, the composition of the Canarian barley gene pool is unique and clearly differentiated from that of barley from Northern Africa and the Mediterranean (Hagenblad et al. 2017). This, coupled with a possible genetic differentiation among islands (Hagenblad et al. 2017), highlights the need for proper morphological characterization and raises important questions concerning how the genetic diversity of Canarian barley is best conserved.

Barley accessions from the seven major islands are currently being held in genebanks both on the Canary archipelago and on mainland Europe, though concerns about the authenticity of some of the accessions, collected in the 1940s and conserved outside the Canary archipelago, have been raised (Hagenblad et al. 2017). During the twenty-first century efforts have been made to collect additional landrace material and to conserve it locally, but the vast majority of assembled accessions have not been genetically or morphologically characterized previously.

In this study, we have genetically and morphologically characterized some of the recently collected landraces. In addition to analyse the diversity of barley accessions currently stored in Canarian genebanks, we wanted to determine to what extent specific accessions and accessions from the same island have unique genetic signatures. We also wanted to see whether suitable conservation strategies could be identified, if a geographic scale suitable for further sampling could be determined and whether duplicate holdings or accessions of high genetic similarity could be identified, all of which may not be critical to conserve should resources for conservation be limited.

\section{Materials and methods}

\section{Materials}

We studied 57 barley landrace accessions collected on all seven islands of the Canarian archipelago (Fig. 1; 


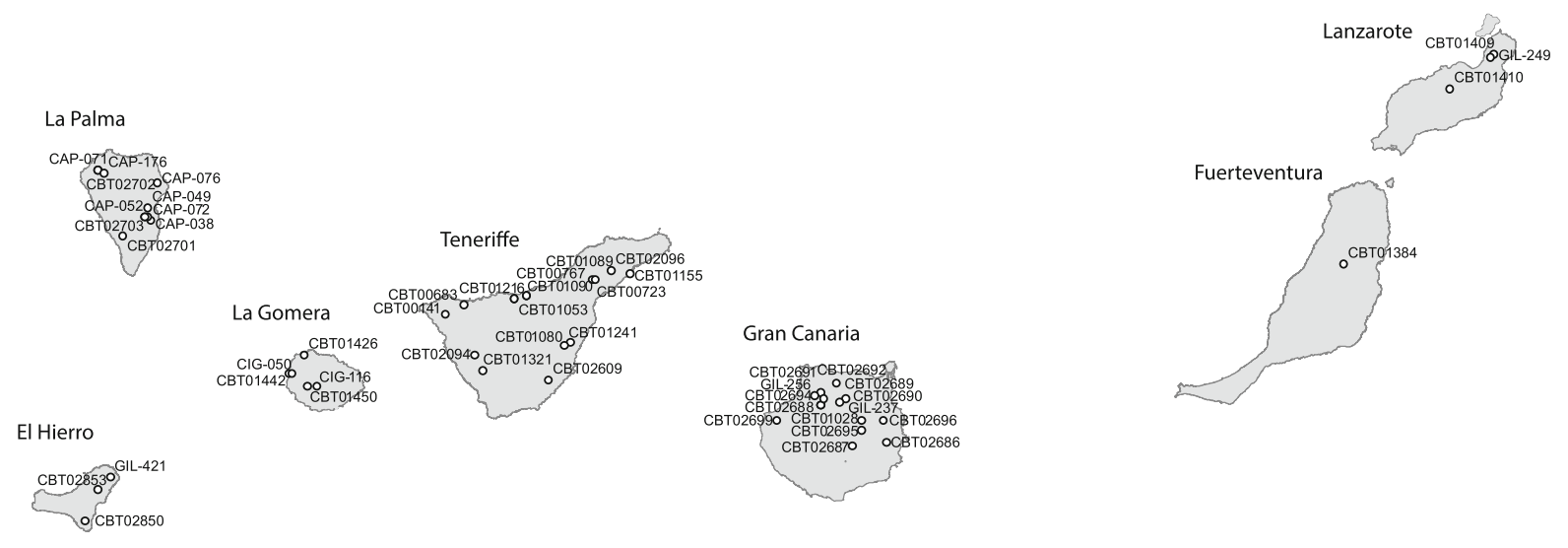

Fig. 1 Map of Canary Island showing the collection sites of the studied accessions

Table 1). The majority of the accessions were obtained from the Centre for the Conservation of the Agricultural Biodiversity of Tenerife (CCBAT), with additional accessions from Centro de Agrodiversidad de La Palma (CAP), and from the private collections of Jaime Gil (CIG, La Gomera and GIL, Lanzarote).

Test cultivation

Cultivation trials were carried out at Candelaria, Tenerife $\left(28^{\circ} 22^{\prime} \mathrm{N}, 16^{\circ} 23^{\prime} \mathrm{W}, 533\right.$ m.a.s.l.) during the 2013 main cropping season (sowing date 18 December 2012). Based on meteorological data, the area received an accumulated precipitation of $147.1 \mathrm{~mm}$ during the trials with most of it falling between February and March. Because of the low precipitation, support irrigation, approximately $120 \mathrm{~mm}$, was necessary. The average temperature was $16.3{ }^{\circ} \mathrm{C}$, with daily temperature ranging between an average minimum $12.6^{\circ} \mathrm{C}$ and an average maximum of $21.5^{\circ} \mathrm{C}$. The soil of the experimental field was saline with an electrical conductivity (EC) of $4.18 \mathrm{mS} \mathrm{cm} \mathrm{cm}^{-1}$ and a $\mathrm{pH}$ of 7.0.

Forty-two barley landraces were morphologically characterized (Table 1). The cultivation was conducted in an augmented design consisting of nonreplicated single-row plots with randomized repetitions of three improved two-row barley cultivars (CBT02711, CBT02712 and CBT02713) in a total of four incomplete blocks. For each accession 350 seeds per $\mathrm{m}^{2}$ were sowed manually in 4- $\mathrm{m}$ long, 4-row plots, with $20 \mathrm{~cm}$ spacing between rows. The trials were managed according to farmers' practice, including land preparation, weeding and harvesting, with no application of fertilizer, pesticides or fungicides.

\section{Morphological characterization}

For the morphological characterization, a list of descriptors was made based on the guidelines of IPGRI (1994), UPOV (1994) and Lasa (2008). Days to maturation and an additional eight traits were measured on a plot basis while plant height and eleven more traits were determined in the laboratory from a sample of 15 main stems per plot (Table 2). For the traits assessed on individual samples the means of the 15 sample plants from each row were used. Descriptive statistics of both quantitative and qualitative traits were calculated using EXCEL 2007. Principal Component Analysis (PCA) carried out for morphological traits was performed using NTSYS pc 2.1.

DNA extraction and genotyping

From each accession leaf tissue from six individual germinated seeds were collected and DNA was extracted using either the Qiagen DNeasy 96 Plant Kit or the Maxwell 16 LEV Plant DNA Kit (Promega). Single nucleotide polymorphism (SNP) genotyping was carried out by LGC Genomics, using the KASP (Competitive Allele Specific PCR) assay method (He et al. 2014; Semagn et al. 2014). In addition to 186 individual plants already genotyped in Hagenblad et al. (2017) 189 new individuals were genotyped for the same 99 SNP markers (described in Hagenblad 


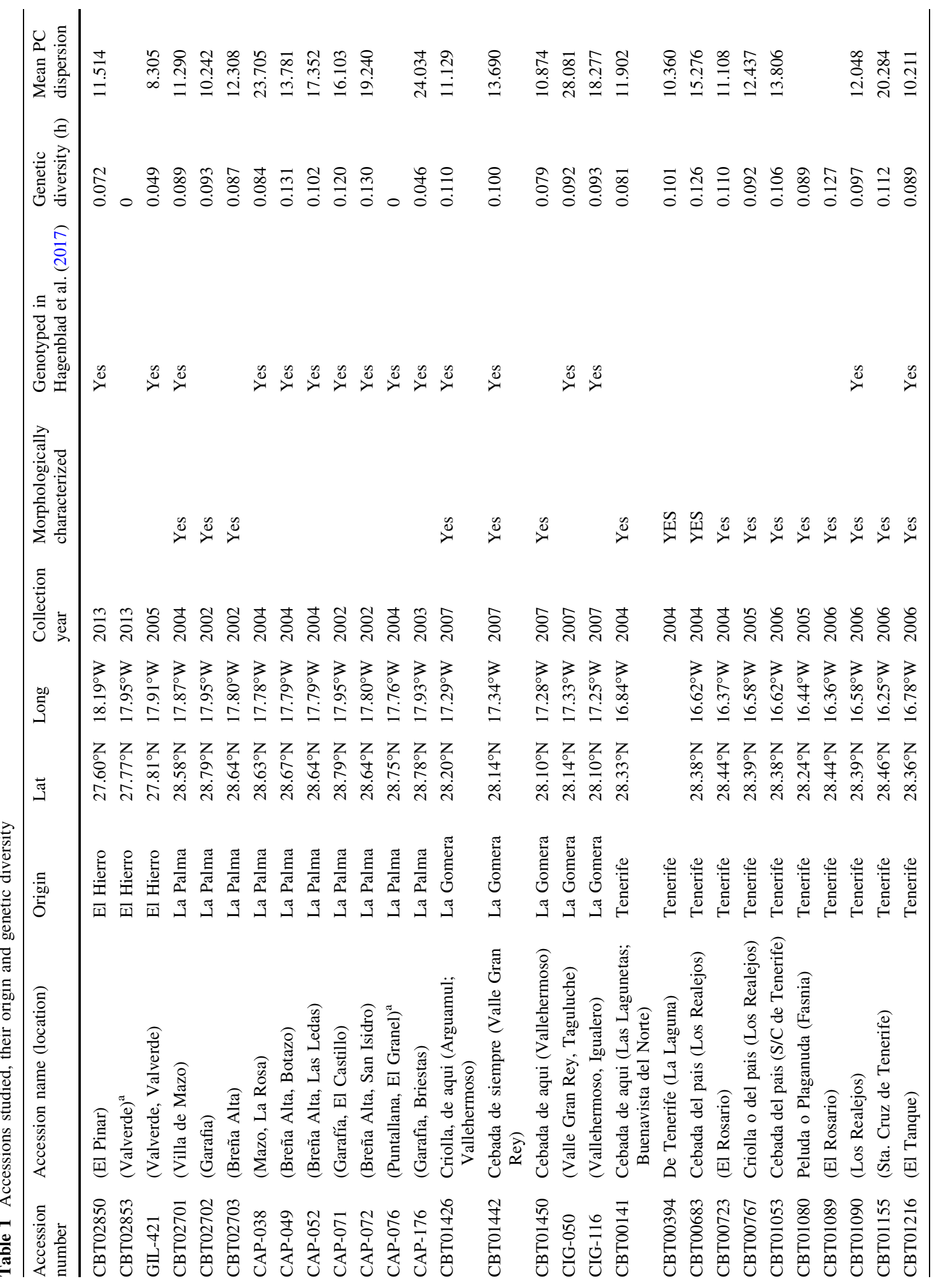




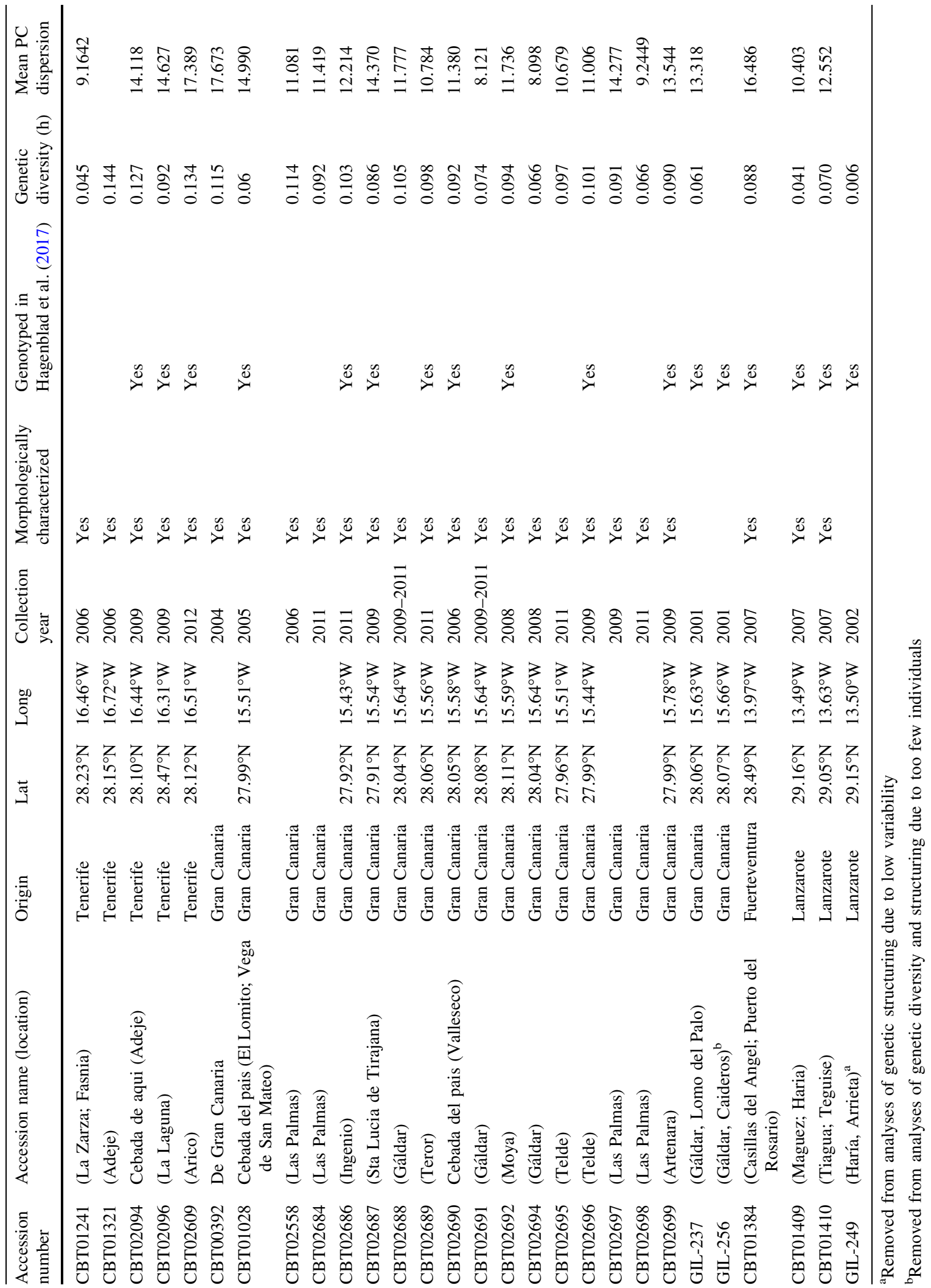


Table 2 Distribution of qualitative traits among Canarian barley landraces

\begin{tabular}{|c|c|c|c|c|c|c|c|c|c|c|}
\hline \multirow[t]{2}{*}{ Trait } & \multirow[t]{2}{*}{ States } & \multicolumn{9}{|c|}{ Number of accessions per state } \\
\hline & & 1 & 2 & 3 & 4 & 5 & 6 & 7 & 8 & 9 \\
\hline Growth habit ${ }^{\mathrm{a}}$ & $3=$ prostrate, $5=$ intermediate, $7=$ erect & - & - & 0 & - & 27 & - & 15 & - & - \\
\hline Stem pigmentation $^{\mathrm{a}}$ & $1=$ green, $2=$ purple & 34 & 8 & - & - & - & - & - & - & - \\
\hline Basal leaf hairiness ${ }^{a}$ & $1=$ presence, $2=$ absence & 42 & 0 & - & - & - & - & - & - & - \\
\hline Auricle pigmentation $^{\mathrm{a}}$ & $1=$ green, $2=$ purple & 38 & 4 & - & - & - & - & - & - & - \\
\hline Spike glaucosity ${ }^{\mathrm{a}}$ & $\begin{array}{l}1=\text { absent or very weak, } 3=\text { weak, } 5=\text { medium, } 7=\text { strong, } \\
9=\text { very strong }\end{array}$ & 8 & - & 25 & - & 6 & - & 3 & - & 0 \\
\hline Spike attitude ${ }^{a}$ & $\begin{array}{l}1=\text { erect, } 3=\text { semi-erect, } 5=\text { horizontal. } 7=\text { semi-recurved, } \\
9=\text { recurved }\end{array}$ & 1 & - & 20 & - & 18 & - & 3 & - & 0 \\
\hline Row number ${ }^{a}$ & $1=$ six-row, 2 = two-row & 40 & 2 & & & & & & & \\
\hline Spike shape ${ }^{a}$ & $3=$ tapering, $5=$ parallel, $7=$ fusiform & - & - & 3 & - & 28 & - & 11 & - & - \\
\hline Spike density ${ }^{\mathrm{b}}$ & $3=$ lax, $5=$ intermediate, $7=$ dense & - & - & 3 & - & 39 & - & 0 & - & - \\
\hline $\begin{array}{l}\text { Glume and glume awn } \\
\text { length }^{\mathrm{b}}\end{array}$ & $1=$ shorter, $2=$ equal, $3=$ longer $($ than kernel) & 3 & 36 & 3 & - & - & - & - & - & - \\
\hline Glume color $^{\mathrm{b}}$ & $1=$ white, $2=$ yellow, $3=$ brown, $4=$ black & 42 & 0 & 0 & 0 & - & - & - & - & - \\
\hline Length of rachilla hairs ${ }^{b}$ & $1=$ short, $2=$ long & 31 & 11 & - & - & - & - & - & - & - \\
\hline Lemma type ${ }^{\mathrm{b}}$ & $1=$ no lemma teeth, $2=$ lemma teeth, $3=$ lemma hair & 2 & 40 & 0 & - & - & - & - & - & - \\
\hline Awn color ${ }^{\mathrm{b}}$ & $\begin{array}{l}1=\text { amber } / \text { white, } 2=\text { yellow, } 3=\text { brown, } 4=\text { reddish, } \\
5=\text { black }\end{array}$ & 16 & 21 & 4 & 1 & 0 & - & - & - & - \\
\hline Awn length ${ }^{\mathrm{b}}$ & $3=$ short, $5=$ medium, $7=$ long & - & - & 3 & - & 29 & - & 10 & - & - \\
\hline Awn pigmentation ${ }^{\mathrm{b}}$ & $1=$ absence, $2=$ presence antocyanin & 39 & 3 & - & - & - & - & - & - & - \\
\hline Lemma awn barbs ${ }^{\text {b }}$ & $3=$ smooth, $5=$ intermediate, $7=$ rough & - & - & 0 & - & 1 & - & 41 & - & - \\
\hline Grain covering $^{\mathrm{b}}$ & $1=$ naked, $2=$ semi-covered, $3=$ covered & 1 & 0 & 41 & - & - & - & - & - & - \\
\hline $\begin{array}{l}\text { Color of aleurone layer } \\
\text { grain }^{\text {b }}\end{array}$ & $1=$ whitish, 2 = weakly colored, $3=$ strongly colored & 5 & 29 & 8 & - & - & - & - & - & - \\
\hline
\end{tabular}

A dash (-) denotes that the state does not exist for that descriptor

${ }^{\mathrm{a}}$ Trait measured on a plot basis

${ }^{\mathrm{b}}$ Trait measured in a sample of 15 mains stems

et al. 2017). In total, genotyping data was obtained for 375 different individuals. The result of the genotyping is available from the Dryad Digital Repository: https:// doi.org/10.5061/dryad.979f850.

Genetic data analyses

Markers with less than $80 \%$ success rate in either of the two genotyping batches were removed (in total seven markers). Thereafter, individuals with less than $80 \%$ success rate in the remaining markers were removed (twelve individuals from nine accessions). Finally, the accession GIL-256 with only two remaining individuals was excluded.

Genetic diversity was estimated as Nei's h (Nei 1973) using a purpose-written perl script. Three accessions, CAP-76, CBT02853 and GIL-249, proved to have no or nearly no genetic diversity and were therefor excluded from analysis of genetic structuring. The software R (R Core Team 2018) was used for statistical testing of diversity levels. In ANOVA accessions from the two easternmost islands, Lanzarote and Fuerteventura, were merged to increase the number of observations, as were accessions from El Hierro and La Gomera, from the southwestern part of the archipelago. $\mathrm{R}$ was also used for carrying out AMOVA using the poppramova command of the library poppr.

Genetic structuring was investigated by calculating pairwise $F_{S T}$ values, through PCA and with the software STRUCTURE (v 2.3.4) (Pritchard et al. 2000; Falush et al. 2003). Wright's F ST $_{\text {(Wright 1951) }}$ 
Table 3 Statistical parameters for quantitative traits of Canarian barley landraces

\begin{tabular}{lrrrr}
\hline & Mean & SD & Minimum & Maximum \\
\hline Days to mature & 151.79 & 8.93 & 114 & 162 \\
Plant height $(\mathrm{cm})$ & 99.92 & 9.39 & 84.58 & 122.53 \\
Spike length $(\mathrm{cm})$ & 7.27 & 1.32 & 4.58 & 10.01 \\
Triplets per spike & 16.81 & 4.13 & 10.61 & 31.54 \\
Grains per spikelet & 2.90 & 0.43 & 1 & 3 \\
\hline
\end{tabular}

was calculated between all pairs of accessions using a purpose-written perl script. PCA of genetic data was carried out using the prcomp command in $\mathrm{R}$ ( $\mathrm{R}$ Core Team 2018). In the PCA, data was either analysed on an accession level or on an individual level, with the number of copies of each allele at each locus for the accession or individual treated as independent variables. The ability to separate accessions from different islands in the PCA was analysed with ANOVA of the coordinates along PC1 and PC2. Within-accession diversity as detected by the PCA was quantified by calculating the PC dispersion statistic according to Forsberg et al. (2015).

STRUCTURE was run using a haploid setting, as recommended for predominantly selfing species by Nordborg et al. (2005), after recoding the limited number of heterozygous loci as missing data. The software was run with a burn-in length of 20,000 iterations followed by 50,000 iterations for estimating the parameters, with 10 repeated runs at each level of predetermined clusters (K), with $\mathrm{K}$ ranging from 1 to 15. The software CLUMPP (v 1.1.2) (Jakobsson and Rosenberg 2007) was used to compare the outcome of individual runs with the Greedy algorithm for $4<\mathrm{K}<6$ and with the LargeKGreedy algorithm for $K \geq 6$. The number of clusters best describing the data was evaluated from the CLUMPP H' values and $\Delta \mathrm{K}$ calculated according to (Evanno et al. 2005). Results were visualized using DISTRUCT (v 1.1) (Rosenberg 2004).

\section{Results}

Morphological characterization

Statistical analysis of the morphological data showed a wide range of variability in plant, spike and grain morphological traits. Among the quantitative traits high variability was observed in plant height $(84.58-122.53 \mathrm{~cm})$, spike length $(4.58-10.01 \mathrm{~cm})$ and number of triplets per spike (10.61-31.54) (Table 3). With the exception of two samples, CBT01080 and CBT01321, the landrace accessions were all six-row and no variation was observed in basal leaf hairiness or glume colour (Table 2). However, variation was observed in spike glaucosity, attitude and shape as well as both awn colour and length. Covered grains were observed in all the landraces except CBT01450, which had naked grains. Number of grains per spike ranged from 30.01 for the two-row accession CBT01321 (31.82 for the six-row CBT00683) to 65.19 for CBT01053.

Principal component analysis of all accessions clearly separated two-row from six-row accessions (data not shown). PCA of only the six-row accessions visualized the high level of variation among landraces (Fig. 2). Considering eigenvalues greater than one, seven principal components (PCs) accounted for $75.46 \%$ of the total variance among the 20 variable morphological characters (supplementary Table 1). Spike length, plant height, triplets per spike and stem pigmentation were the main contributors to the first PC, which explained $19.79 \%$ of total variation. An additional $14.38 \%$ of the variation, accounted for by the second PC, was due to contributions from awn length and spike shape. The third principal component, which explained $11.45 \%$ of the variation, had high loadings from auricle and awn pigmentation. With the exception of the two accessions from Lanzarote the morphological diversity showed little evidence of distinguishing between accessions from different islands along the first two PCs (Fig. 2).

Functional markers

Genotyping functional markers corroborated the morphological observation that CBT01080 and 


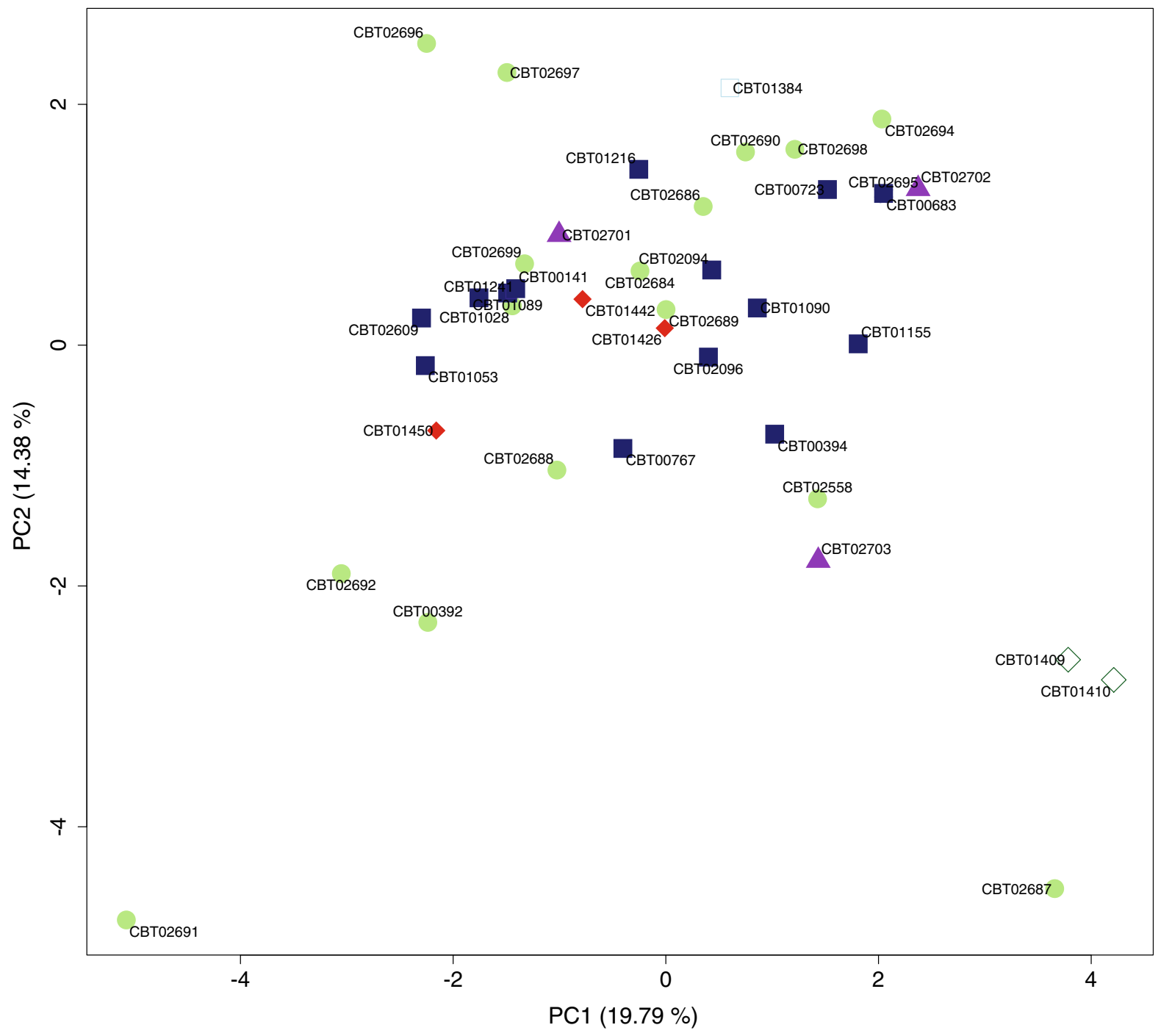

Fig. 2 Distribution of six-row barley landraces along the first and second principal components (PCs) based on characterization of morphological traits. Accessions from the same island are denoted by the same colour and shape: light green, filled

CBT01321 were two-row barley. Both these accessions carried a $\mathrm{C}$ at Int-c_SNP124 and differed from the remaining accessions. At Vrs1 E152F_S, also affecting row-type, all of the individuals of CBT01080 and CBT01321 had the $\mathrm{G}$ allele as did five individuals of CAP-76 and one individual of CBT01089. All accessions exclusively carried the $\mathrm{C}$ allele at $H v N A M$ 2_SNP798, which is associated with high protein content. The majority of individuals further carried the C allele at Lhcb1_SNP907, which has been associated with a high number of grains per spike, the exceptions circles = Gran Canaria; dark green, open diamonds = Lanzarote; light blue, open square $=$ Fuerteventura; blue, filled squares = Tenerife; purple, filled triangles = La Palma; red, filled diamonds $=$ La Gomera. (Color figure online)

being the two-row accessions CBT01080 and CBT01321 and three individuals of CAP-76 (not morphologically characterised). CBT01080 and CBT01321 had the lowest number of grains per spike (30.01 and 31.54, respectively) of all the morphologically characterized accessions as could be expected from them being the only two-row accessions. All sixrow accessions carried the early flowering allele at ppd-H1_Jones_SNP48. 
Table 4 Diversity measures for accessions from different islands and island groups

\begin{tabular}{lclc}
\hline Island (group) & Number of accessions & Average within-accession diversity (variance) & Total diversity \\
\hline Gran Canaria & 19 & $0.092(0.000)$ & 0.124 \\
Tenerife & 18 & $0.104(0.000)$ & 0.215 \\
Tenerife six-row & 16 & $0.103(0.000)$ & 0.134 \\
El Hierro & 4 & $0.040(0.001)$ & 0.069 \\
Lanzarote & 3 & $0.039(0.001)$ & 0.104 \\
La Palma & 10 & $0.088(0.001)$ & 0.126 \\
La Gomera & 5 & $0.095(0.000)$ & 0.116 \\
Fuerteventura & 1 & $0.088(\mathrm{NA})$ & 0.088 \\
Lanzarote and Fuerteventura & 6 & $0.051(0.001)$ & $0.074(0.001)$ \\
El Hierro and La Gomera & 9 & & \\
\hline
\end{tabular}

Table 5 Results of AMOVA of genetic diversity of accessions from different islands

\begin{tabular}{llll}
\hline & \% variance explained & Phi & $p$ \\
\hline Among islands & 11.97 & 0.120 & 0.001 \\
Among accessions within islands & 10.62 & 0.120 & 0.001 \\
Within accessions & 77.41 & 0.226 & 0.001 \\
\hline
\end{tabular}

Genetic diversity

Heterozygous loci were detected in 27 individuals. The highest number of heterozygous loci (seven, $0.07 \%$ ) was detected in one individual each of CBT01426 and CBT02094. Within-accession genetic diversity ranged from 0 (CAP-76 and CBT02853) to 0.144 (CBT01321) (Table 1). Genetic diversity was not significantly correlated with collection year $(\mathrm{c}=-0.019, p=0.891)$.

The within-accession diversity differed significantly among island groups (Table 4) (ANOVA $p<0.05$ ) with the lowest within-accession diversity being observed for accessions from the LanzaroteFuerteventura group (average $\mathrm{h}=0.051$ ) and the highest for accessions from Tenerife (average $\mathrm{h}=0.104)$. When accessions from the easternmost islands (Lanzarote and Fuerteventura) were excluded within-accession diversity was no longer different among island groups (ANOVA, $p=0.092$ ). The total genetic diversity was lowest on Fuerteventura $(\mathrm{h}=0.088)$ and highest on Tenerife $(\mathrm{h}=0.215$ and 0.134 including and excluding two-row accessions respectively) (Table 4).

AMOVA showed that the majority of the genetic diversity among the six-row accessions (77.4\%) was contained within accessions with equal amount of diversity among islands (12.0\%) and among accessions within islands (10.6\%) (Table 5). Equal amount of variation among accessions and islands and a majority of the variation within accessions were also found when the accessions from the eastern islands of Lanzarote and Fuerteventura were excluded.

Genetic differentiation quantified by $\mathrm{F}_{\mathrm{ST}}$

Genetic differentiation was quantified by calculating $\mathrm{F}_{\mathrm{ST}}$ values between all pairs of accessions (supplementary Table 2). Pairwise $F_{S T}$ values ranged from 0.038 between the Gran Canaria accessions CBT01028 and CBT02688 to 0.651 between the Lanzarote accession CBT01409 and CBT01080 from Tenerife (supplementary Table 2). The two-row CBT01080 and CBT01321, but to a certain extent also CBT01409, had high $\mathrm{F}_{\mathrm{ST}}$ values when compared with most other accessions (supplementary Table 2).

$\mathrm{F}_{\mathrm{ST}}$ values between pairs of accessions on the same island differed between islands. ANOVA showed that $\mathrm{F}_{\mathrm{ST}}$ values were significantly higher on Tenerife (mean 0.228) than on La Gomera (0.121), Gran Canaria (0.144) and La Palma (0.128) (the islands for which a sufficient number of comparisons were available, $p \ll 0.001$ ). However, after removal of the two-row accessions islands no longer differed in their 
a

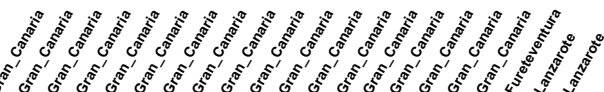

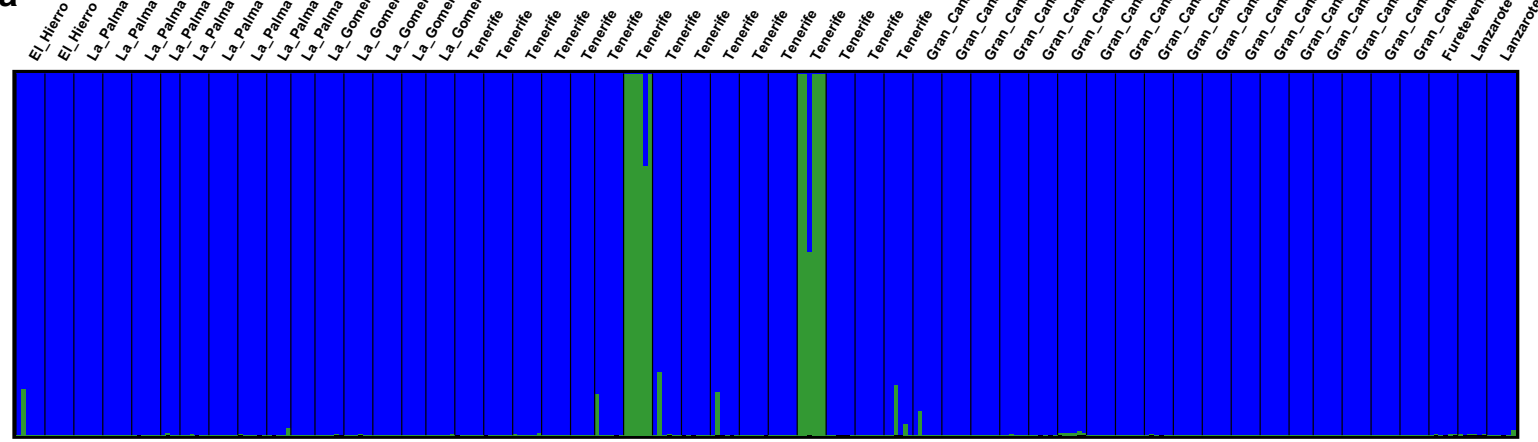

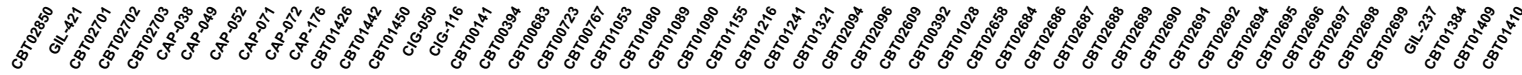

\section{b}

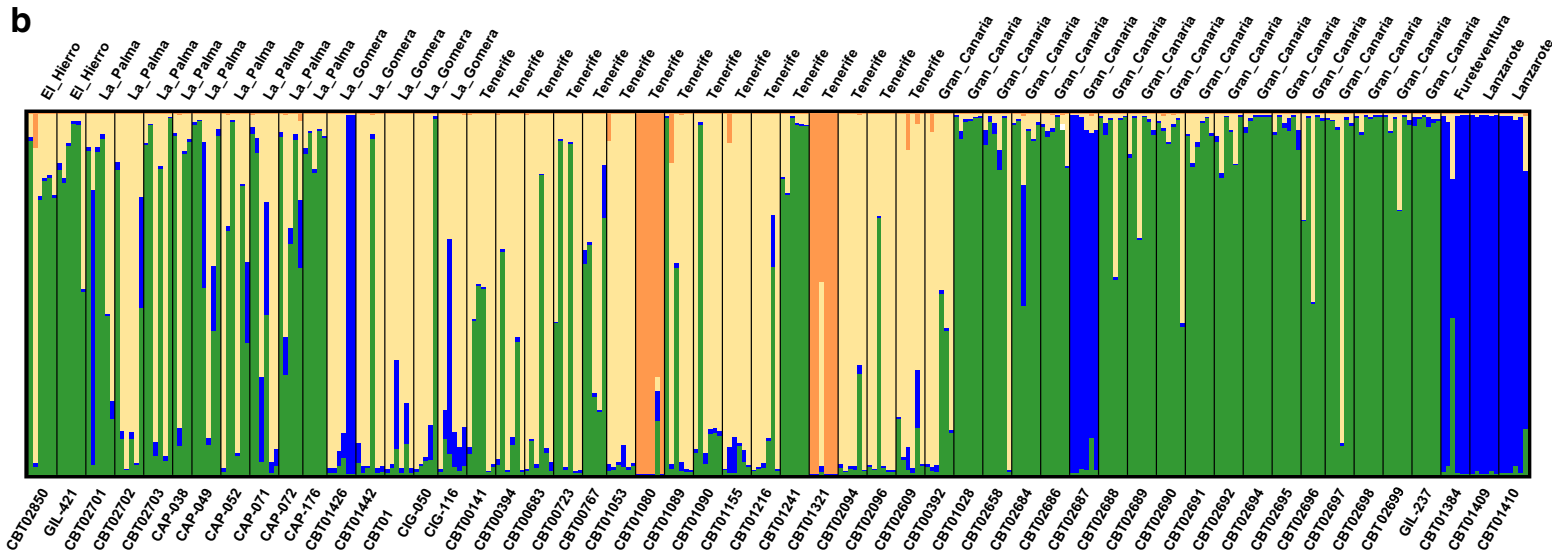

Fig. 3 Results of STRUCTURE analysis for $\mathbf{a} \mathrm{K}=2$ and $\mathbf{b}$ $\mathrm{K}=4$. Each individual is depicted by a vertical line segmented into $\mathrm{K}$ coloured sections. The length of each section is

within-island $\mathrm{F}_{\mathrm{ST}}$ values (ANOVA $p=0.228$ ). $\mathrm{F}_{\mathrm{ST}}$ values between accessions on different islands were significantly higher than between pairs of accessions on the same island ( $t$ test $p<0.05$ for all accessions, $p \ll 0.001$ excluding CBT01080, CBT01321 and CBT01409).

Among island population structure

In STRUCTURE analysis of all accessions $\Delta \mathrm{K}$ and CLUMPP $\mathrm{H}$ values indicated that population structure was best described by two clusters $(\mathrm{K}=2)$ but with high support also for three and four clusters. At $\mathrm{K}=2$ the two-row accessions CBT01321 and CBT01080 were separated from the remaining accessions (Fig. 3a). At $\mathrm{K}=4$ additional clusters had formed proportional to the estimated membership coefficient (Q) of the individual accession to each one of the K clusters. Thin black vertical lines separate different accessions

with one consisting of accessions from the eastern islands Lanzarote and Fuerteventura but also CBT02687 from Gran Canaria (blue in Fig. 3b), another cluster consisting primarily of accessions from Gran Canaria and El Hierro (green in Fig. 3b) and a final cluster primarily consisting of accessions from Tenerife and La Gomera (yellow in Fig. 3b). Many accessions showed mixed clustering, in particular accessions from La Palma.

In PCA of accession-level allele frequencies PC1 separated the two-row accessions (CBT01321 and CBT01080) from all other accessions (data not shown). In PCA of only six-row barley, PC2 clearly separated CBT01089 from all other accessions (data not shown). After removing also CBT01089, PC1 primarily separated eastern accessions (Lanzarote and 


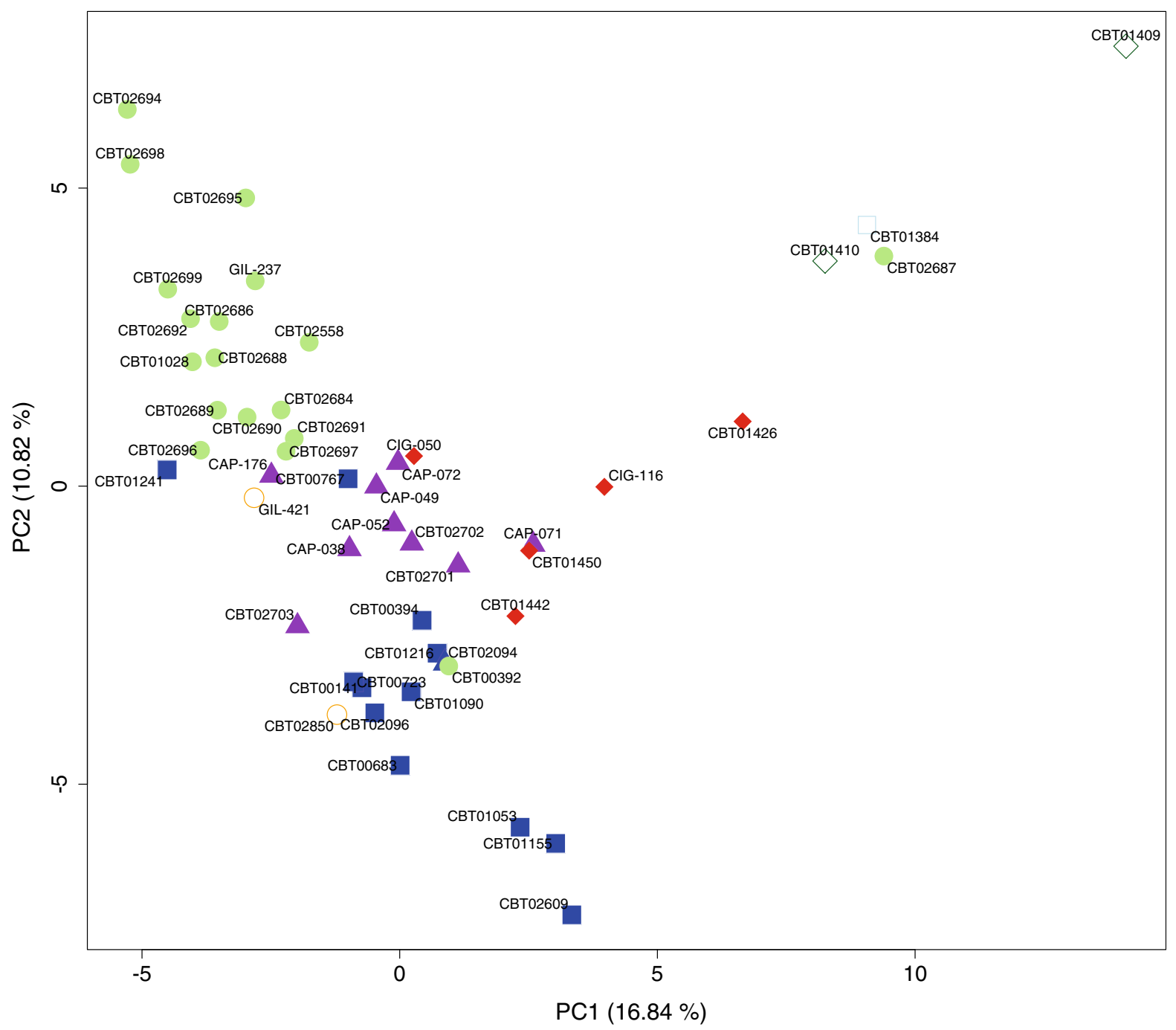

Fig. 4 PCA of six-row accessions after excluding CBT1080. Accessions from the same island are denoted by the same colour and shape as in Fig. 2 and with orange, open circles denoting El Hierro. (Color figure online)

Fuerteventura, dark green open diamonds and light blue open squares respectively in Fig. 4) from western accessions. Accessions from the western islands were to a certain extent separated along PC2 with accessions from Gran Canaria (light green filled circles in Fig. 4), Tenerife (blue filled squares in Fig. 4) and accessions from La Palma (purple filled triangles in Fig. 4) and La Gomera (red filled diamonds in Fig. 4) showing varying degrees of clustering (Fig. 4).

ANOVA of the first two PC coordinates for accessions from the different islands showed that the two PCs together were able to separate accessions from most islands from each other $(p \ll 0.001$ for both PCs). Only accessions from the three westernmost islands (El Hierro-La Gomera group and La Palma) were not significantly separated from each other along either of the first two PCs (both $p>0.05$ ) (supplementary Table 3). The observations remained true when excluding the easternmost islands (ANOVA PC1 $p<0.01$, PC2 $p \ll 0.001)$.

Although the morphological PCA showed little clustering according to island, comparing the results of PCA of morphological and genetic data, respectively, for those six-row accessions for which both types of data were available showed significant correlation between the first principal component of the genetic 
PCA and the first two principal components of the morphological PCA (genetic PC1 vs morphological PC1 $\mathrm{c}=0.394, p<0.05 ;$ vs morphological PC2 $\mathrm{c}=-0.387, p<0.05)$.

PCA of individual genotypes of six-row accessions (excluding CBT01089) showed a relatively high level of overlap between accessions from the same island, but to a lesser degree among islands along the first two principal components (supplementary figure 1). The within-accession distribution of individuals in the PC space was quantified with the PC dispersion statistics (Table 1). Mean PC dispersion was not significantly correlated with the diversity of the accession $(p=0.102)$. The lack of correlation was caused by three accessions with unusually high mean PC dispersion (CAP176, CAP38 and CIG50), i.e. where the genetic diversity was not evenly distributed among loci and individuals, and after removal of these accessions genetic diversity and mean PC dispersion were significantly correlated $(c=0.452, p<0.01)$. ANOVA showed no significant difference in accession mean PC dispersion between islands $(p=0.108$ and 0.062 with and without easternmost accessions, respectively).

Within-island geographic structure

Within-island STRUCTURE analyses of the accessions from Gran Canaria, Tenerife and La Palma, the three islands from which the highest number of accessions were available, did not show any clear geographic structure within the islands (data not shown). For Gran Canaria and La Palma, coordinates along the first two PC were not correlated with either latitude or longitude (all comparisons $p>0.05$ ). For Tenerife latitude was significantly correlated with PC2 $(p<0.05)$ but no other correlations could be detected (all other comparisons $p>0.05$ ).

Genetic distance $\left(\mathrm{F}_{\mathrm{ST}}\right)$ was only significantly correlated with geographic distance on La Gomera (c $=0.697, p<0.05$, all other Islands $p>0.05$ ). Mantel test of genetic and geometric distances were significant for La Palma and La Gomera (both $p<0.05$ ), but not for Tenerife or Gran Canaria (both $p>0.05, \quad p>0.05$ excluding CBT01080 and CBT01321).

\section{Discussion}

Genetic identity of landrace accessions

The genetic characterisation suggested that accessions were in general relatively homogenous as shown by the relatively close clustering in the individual-level PCA (supplementary figure 1) and the few outliers for mean PC dispersion (Table 1). An exception was CAP-076 (which was not morphologically characterized) which included individuals with both two-row and six-row genotypes as well differing in the otherwise generally monomorphic marker for Lhcbl. Similarly, one of the individuals of the accessions CBT01089 carried a Vrs1 allele associated with the two-row type. Although genotyping of the Int- $C$ locus suggested it to be six-row, CBT01089 clustered away from all other six-row accessions in the PCA (but not in the STRUCTURE analysis). CBT01089 had among the higher levels of genetic diversity and it is conceivable that the accession has a hybrid origin. Whether CBT01089 is the results of conscious mixing of seed from landraces is not known to us. In the case of CAP-076 the absence of genetic diversity among the neutral markers argues against it being the result of seed mixing. Instead this accession, together with the similarly low variable CBT0283 and GIL-249, seems to have been subjected to a major bottleneck, either during in situ cultivation or during collection for the genebank. Loss of genetic diversity over the limited time in genebank storage seems a less likely cause for the absence of genetic diversity in these accessions and in general accessions with a longer history of genebank conservation did not have lower levels of genetic diversity.

For some of the landraces the results of the genotyping gave rise to concerns about the reliability of the provenance of the accessions. One of the accessions genotyped by Hagenblad et al. (2017), CBT02687 from Gran Canaria, clustered among accessions from Lanzarote and Fuerteventura. Among the accessions genotyped in this study CBT00392, also from Gran Canaria clearly clusters among accessions from Tenerife (Fig. 4). It seems likely that these accessions descend from landrace material being traded between islands in relatively recent times. Similar conclusions can also be made regarding CBT01241 and CBT00767, both from Tenerife, but clustering close to Gran Canarian accessions (Fig. 4). 
The agronomical value of these accessions does not depend on their lack of similarity to other accessions from the same islands, and their conservation value should not be discounted on these grounds, but we advise against using such accessions for studying the evolutionary or agronomical history of barley cultivation.

Several pairs of accessions showed high genetic similarity, such as low pairwise $\mathrm{F}_{\mathrm{ST}}$ values or clustering in close proximity in the PCA. Should reductions in the number of conserved accessions be needed these may be candidate accessions. However, we caution against relying solely on genetic diversity as a basis for removing near duplicates in genebank holdings. The accession pair CBT02691 and CBT02697, for example, originates on Gran Canaria (Gáldar and Las Palmas respectively), their pairwise $\mathrm{F}_{\mathrm{ST}}$ value is low (0.081) and they cluster closely together in the genotype-based PCA. In terms of morphology, however, they fall at opposite end of the second principal component in the morphology-based PCA. In fact, CBT02691 must be considered to be rather unique in terms of morphological traits, for example being the only accession with intermediate awn barbs and lacking lemma teeth. Removing it from genebank holdings on the basis of its similarity to CBT02697 in terms of neutral genetic variation would have led to the loss of valuable morphologic diversity. Similar cases can be made for CBT01450 and CBT02687 with unique traits like naked grains and reddish awns respectively. Such singular morphological traits must be taken into account to uphold the diversity of barley in the Canary archipelago in genebank collections.

Our findings corroborate well with Harlan's (1975) classic description of landraces as being diverse but yet with a certain genetic integrity. The distinctiveness of most landraces also suggest that it might be worth the effort to gather more landrace barley in the Canary archipelago. Recent re-collections of in situ landraces in e.g. Catalonia (Casals et al. 2017) and in Sweden (Hagenblad et al. 2013; Solberg et al. 2015) show that new material rather than duplicates are found at new inventories.

Two- and six-row barley on the Canary archipelago and the continent

Morphological variation has long been the basis for classifying different types of barley (Mansfeld 1950;
Kobyljanskij and Lukjanova 1990). Our characterization showed that most landrace accessions were of the six-row type. The cultivation of six-row barley in the Canary archipelago dates back to pre-Hispanic times (Morales et al. 2014) and the currently cultivated barley shows high genetic similarity to pre-Hispanic barley (Hagenblad et al. 2017). The distinctiveness of the Canarian barley, compared to the Spanish barley core collection, was confirmed in this study by several morphological characters. For example, Canarian landraces showed an absence of hairiness in basal leaves and presence of lemma teeth in contrast to the majority of accessions in the Spanish core collection (Lasa 2008). The unique genetic signature of Canarian barley discovered by Hagenblad et al. (2017) is thus coupled with a particular morphological appearance. The superior grain and straw yield that has been reported for Canarian landraces when compared with commercial varieties (Hernández et al. 2013) suggest differentiation also in genes underlying adaptation to the insular cultivation conditions.

In addition to the six-row accessions, two accessions (CBT01080 and CBT01321) were found to be of the two-row type. PCA of both morphological traits and genetic diversity showed a clear division between two-row and six-row landraces, similar to what has previously been reported for continental barley in general and Nordic barley (Malysheva-Otto et al. 2006; Kolodinska Brantestam et al. 2007; Jones et al. 2011). The history of the two-row accessions is not known, but it seems likely that they descend from landraces brought to Tenerife after the Hispanic colonization. Future comparisons with Iberian and other continental two-row barley may be able to confirm such a hypothesis.

\section{Sampling strategies for barley conservation}

Genetic and morphological characterization each comes with its own set of benefits and disadvantages. Morphological characterization can be labour intensive but may provide agronomically useful prebreeding data. Genotyping will instead reveal the general genetic diversity of an accession and may highlight material suitable for further screening of non-characterized morphological traits. The landraces studied here exhibited a high level of variation in a wide range of characters both in the vegetative part, the spike and the grain (Tables 2, 3). We found 
significant correlations between morphological traits and neutral genetic markers when analysed with PCA and although the correlations were not very strong, possibly as a result of the limited number of markers used, we can conclude that at least some aspects of the morphological diversity were captured by the neutral genetic markers used in this study. A preliminary genetic screening may allow for a more in-depth morphological characterization of a reduced number of accessions of high interest.

In this study we could, with the addition of novel accessions, confirm the findings of Hagenblad et al. (2017) of relatively distinct genetic structuring primarily between eastern (Lanzarote and Fuerteventura) and western islands, but to a certain extent also between Gran Canaria and Tenerife and the westernmost islands (Fig. 4). The differentiation between landraces from eastern and western islands was to a minor extent captured by the morphological characterization (Fig. 2), and previous studies have shown how landraces originating from different islands differ in their macromineral content (Panizo et al. 2016). It is therefore clear that any conservation effort for the archipelago needs to involve sampling on all the different islands. In this study a limited number of accessions were investigated from Lanzarote, Fuerteventura and El Hierro. Notwithstanding, the results of the individual and accession based PCAs (Fig. 4, supplementary Fig. 1) suggest these islands too contain valuable genetic resources. Efforts to conserve additional landraces from El Hierro and the easternmost islands should be worthwhile.

The diversity analysis, using STRUCTURE, suggested that accessions from the central islands, Gran Canaria and Tenerife were genetically fairly uniform, each belonging mostly to a distinct genetic cluster. This was less the case for the westernmost islands, where in particular individuals from accessions from La Palma were assigned to multiple clusters, in spite of the fact that the average within-accession diversity was lower on La Palma than on Gran Canaria and Tenerife. In addition, two of the three accessions with the highest mean PC dispersion, that is the accessions where individuals were genetically the most different from each other, also indicative of a diverse genetic background, came from La Palma. In the sixteenth century almost no barley was cultivated on La Palma and it is known that grain was imported from Tenerife and Lanzarote (Cabrera 2007). Our results support an origin of La Palma barley from Tenerife, but also from Gran Canaria rather than Lanzarote.

Although distinct genetic signatures were detected for several of the different islands AMOVA suggested that as much genetic variation could be found among accessions within islands as among islands. Repeated sampling from a single island could thus be as valuable as sampling from different islands. Genetic structuring was, however, less clear within islands making the identification of general sampling strategies difficult. Only on La Palma and La Gomera did a Mantel test detect significant isolation by distance and only on La Gomera was geographic and genetic distances significantly correlated. On most islands, relatively high $\mathrm{F}_{\mathrm{ST}}$ values (in excess of 0.150 ) could be found both between accessions originating from tens of kilometres apart as well as from accessions originating from locations only a couple of kilometres from each other. For example, all six comparisons between the three accessions from Gáldar on Gran Canaria had $\mathrm{F}_{\mathrm{ST}}$ values of 0.160 or higher $(0.212$ being the highest). This contrasts for example barley landraces on Sardinia where the isolation by distance effect was much more evident (Bellucci et al. 2013). The rugged topography of many of the islands in the archipelago has likely meant that, historically, human travel, and as a consequence seed exchange, has not been a linear function of geographic distance but rather varied among places depending on their surrounding orography. From a conservation perspective, sampling landraces cultivated at close geographic proximity, but for example across a steep ravine, may be as rewarding in terms of genetic diversity as choosing locations further apart but across easily navigated land.

\section{Conclusions}

We have described the distribution of morphological and genetic diversity in landrace barley, within and among Canary islands. Our results show the need for conservation of landraces from all islands and the need to include both morphological and genetic diversity as a basis when developing conservation strategies. Canarian barley landraces are clearly differentiated from continental accessions, and to a certain extent also among islands, both in terms of genetic diversity and in morphological traits. This, in addition to their 
direct descent from barley of pre-Hispanic origin (Hagenblad et al. 2017), provides an important added value that can be used to promote their market value, taking advantage of the increase in cereal cultivation that has occurred in the archipelago recently. Consumers are becoming increasingly aware of the benefits of supporting local products, not only for sustainable food production and to favour the local economy, but also to participate in the conservation of the agricultural landscape and the genetic heritage of the Canary Archipelago.

Acknowledgements The authors would like to thank the Olle Engkvist Byggmästare foundation and the Royal Swedish Academy of Letters, History and Antiquities for financial support. The authors would also like to thank Ida Gustafson for help in the lab and an anonymous reviewer for suggestions that significantly improved the presentation of the content.

\section{Compliance with ethical standards}

Conflict of interest The authors declare that they have no conflict of interest.

Open Access This article is distributed under the terms of the Creative Commons Attribution 4.0 International License (http:// creativecommons.org/licenses/by/4.0/), which permits unrestricted use, distribution, and reproduction in any medium, provided you give appropriate credit to the original author(s) and the source, provide a link to the Creative Commons license, and indicate if changes were made.

\section{References}

Afonso D, Castro N, González A, Lorenzo R, Medina C, Monterrey A, Morera M, Ríos D, Tascón C (2012) Variedades agrícolas tradicionales de Tenerife y La Palma. Gráficas Sabater, Santa Cruz de Tenerife

Atoche Peña P (2013) Consideraciones en relación con la colonización protohistórica de las Islas Canarias. Anu Estud Atl 59:519-562

Bellucci E, Bitocchi E, Rau D, Nanni L, Ferradini N, Giardini A, Rodriguez M, Attene G, Papa R (2013) Population structure of barley landrace populations and gene-flow with modern varieties. PLoS ONE 8:e83891

Cabrera ML (2007) El abastecimiento de cereal en La Palma (1550-1650). Mus Canar 62:191-222

Casals J, Casañas F, Simó J (2017) Is it still necessary to continue to collect crop genetic resources in the Mediterranean area? A case study in Catalonia. Econ Bot 71:330-341

Evanno G, Regnaut S, Goudet J (2005) Detecting the number of clusters of individuals using the software STRUCTURE: a simulation study. Mol Ecol 14:2611-2620
Falush D, Stephens M, Pritchard JK (2003) Inference of population structure using multilocus genotype data: linked loci and correlated allele frequencies. Genetics 164:1567-1587

Forsberg NE, Russell J, Macaulay M, Leino MW, Hagenblad J (2015) Farmers without borders: genetic structuring in century old barley (Hordeum vulgare). Heredity 114:195-206

Fregel R, Pestano J, Arnay M, Cabrera VM, Larruga JM, González AM (2009) The maternal aborigine colonization of La Palma (Canary Islands). Eur J Hum Genet 17:1314-1324

González JG, Hernández MP, Torres RN, Rodríguez ER, Betancort MAP (2005) Los cultivos tradicionales de la Isla de Lanzarote: los granos: diversidad y ecología: Servicio de Patrimonio Histórico, Cabildo de Lanzarote

Hagenblad J, Boström E, Nygårds L, Leino MW (2013) Genetic diversity in local cultivars of garden pea (Pisum sativum L.) conserved 'on farm' and in historical collections. Genet Resour Crop Evol 61:413-422

Hagenblad J, Morales J, Leino MW, Rodríguez-Rodríguez AC (2017) Farmer fidelity in the Canary Islands revealed by ancient DNA from prehistoric seeds. J Archaeol Sci 78:78-87

Harlan JR (1975) Our vanishing genetic resources. Science 188:618-621

He C, Holme J, Anthony J (2014) SNP genotyping: the KASP assay. In: Fleury D, Whitford R (eds) Crop breeding: methods and protocols. Springer, New York, pp 75-86

Hernández G, Afonso D, Ríos D (2013) Evaluación morfoagronómica de las variedades locales de cebada (Hordeum vulgare L.) de Canarias. Universidad de La Laguna, San Cristóbal de La Laguna

Instituto Canario de Estadística [ISTAC] (2018) http://www. gobiernodecanarias.org/istac/

IPGRI (1994) Descriptors for barley (Hordeum vulgare L.). International Plant Genetics Resources Institute, Rome

Jakobsson M, Rosenberg NA (2007) CLUMPP: a cluster matching and permutation program for dealing with label switching and multimodality in analysis of population structure. Bioinformatics 23:1801-1806

Jones H, Civan P, Cockram J, Leigh FJ, Smith LM, Jones MK, Charles MP, Molina-Cano JL, Powell W, Jones G et al. (2011) Evolutionary history of barley cultivation in Europe revealed by genetic analysis of extant landraces. BMC Evol Biol 11:320

Kobyljanskij V, Lukjanova M (1990) Jačmen [Barley]. In: Krivčenko V (ed) Kul'turnaja Flora SSSR. Agropromizdat, Leningrad

Kolodinska Brantestam A, Bothmer R, Dayteg C, Rashal I, Tuvesson S, Weibull J (2007) Genetic diversity changes and relationships in spring barley (Hordeum vulgare L.) germplasm of Nordic and Baltic areas as shown by SSR markers. Genet Resour Crop Evol 54:749-758

Lasa JM (2008) Spanish barley core collection. Instituto Nacional de Tecnología Agraria y Alimentaria, Madrid

Malysheva-Otto LV, Ganal MW, Röder MS (2006) Analysis of molecular diversity, population structure and linkage disequilibrium in a worldwide survey of cultivated barley germplasm (Hordeum vulgare L.). BMC Genet 7:6

Mansfeld R (1950) Das morphologische System der Saatgerste Hordeum vulgare L. sl. Der Züchter 20:8-24 
Morales J (2010) El uso de las plantas en la prehistoria de Gran Canaria: alimentación, agricultura y ecología. Cabildo Gran Canaria, Gran Canaria

Morales J, Rodríguez A, Alberto V, Machado C, Criado C (2009) The impact of human activities on the natural environment of the Canary Islands (Spain) during the preHispanic stage (3rd-2nd Century BC to 15 th Century AD): an overview. Environ Archaeol 14:27-36

Morales J, Rodríguez-Rodríguez A, del Cristo G-MM, MartínRodríguez E, Henríquez-Valido $\mathrm{P}$, del-Pino-Curbelo $\mathrm{M}$ (2014) The archaeobotany of long-term crop storage in northwest African communal granaries: a case study from pre-Hispanic Gran Canaria (cal. ad 1000-1500). Veg Hist Archaeobot 23:789-804

Nei M (1973) Analysis of gene diversity in subdivided populations. Proc Natl Acad Sci U S A 70:3321-3323

Nordborg M, Hu TT, Ishino Y, Jhaveri J, Toomajian C, Zheng H, Bakker E, Calabrese P, Gladstone J, Goyal R et al (2005) The pattern of polymorphism in Arabidopsis thaliana. PLoS Biol 3:e196

Panizo M, Afonso D, Ríos D, Rodríguez E (2016) Composición mineral de las variedades locales de cebadas canarias. AE. Agricultura y ganadería ecológica 25:20-21

Pasam RK, Sharma R, Walther A, Ozkan H, Graner A, Kilian B (2014) Genetic diversity and population structure in a legacy collection of spring barley landraces adapted to a wide range of climates. PLoS ONE 9:e116164

Pritchard JK, Stephens M, Donnelly P (2000) Inference of population structure using multilocus genotype data. Genetics 155:945-959

R Core Team (2018) R: a language and environment for statistical computing. R Foundation for Statistical Computing, Vienna, Austria. https://www.R-project.org/
Rodríguez-Rodríguez A, Morales-Mateos JB, del Pino CM, Naranjo-Mayor YN, Rodríguez EM, González-Marrero M (2011) Espacios de producción especializada, excedentes y estratificación social en la Gran Canaria pre-europea. Tabona: Revista de prehistoria y de arqueología 19:101-123

Rodriguez-Varela R, Gunther T, Krzewinska M, Stora J, Gillingwater TH, MacCallum M, Arsuaga JL, Dobney K, Valdiosera C, Jakobsson M et al (2017) Genomic analyses of pre-european conquest human remains from the canary islands reveal close affinity to modern North Africans. Curr Biol 27(3396-3402):e3395

Rosenberg NA (2004) DISTRUCT: a program for the graphical display of population structure. Mol Ecol Notes 4:137-138

Sánchez-Manzano Suárez F (1984) La Laguna, 1800-1860: un estudio de historia agraria. Ediciones IDEA, Santa Cruz

Semagn K, Babu R, Hearne S, Olsen M (2014) Single nucleotide polymorphism genotyping using Kompetitive Allele Specific PCR (KASP): overview of the technology and its application in crop improvement. Mol Breed 33:1-14

Solberg SO, Brantestam AK, Olsson K, Leino MW, Weibull J, Yndgaard F (2015) Diversity in local cultivars of Pisum sativum collected from home gardens in Sweden. Biochem Syst Ecol 62:194-203

UPOV (1994) International union for the protection of new varieties of plants: guidelines for the conduct of tests for distinctness, uniformity and stability, barley (Hordeum vulgare L.), Geneva, 1994

Wright S (1951) The genetical structure of populations. Ann Eugen 15:323-354

Yahiaoui S (2006) La Coleccion nuclear espanola de cebada: diversidad genetica y potencial agronomico. [Ph.D. Thesis]. [Lleida]: Universitat de Lleida 